\title{
Research on Application of "People-Oriented" Educational View in Contemporary College Students Sports Teaching Reform
}

\author{
Xiaoxin Wang \\ Department of Physical Education, Xi'an International University, Xi'an, 710077, China
}

Keywords: Sports teaching; "people-oriented" educational view; humanistic spirit

\begin{abstract}
Since the rapid economic development, especially in the 21 st century, in addition to paying attention to the basic education of college students, the "people-oriented" idea is also highlighted. The acceptance of education is not just for entering a higher school and having living skills, but for giving full to the personal ability and improving the personal quality. For the development of contemporary society, the education is the cornerstone of social development, which can develop people's potential and give play to people's value.
\end{abstract}

\section{Introduction}

The education is unconsciously influenced and the good education and teaching method can correctly guide the college students to have correct value and promote the social harmonious development. However, the contemporary college student education should implement "people-oriented" core thought in terms of teaching philosophy to promote the balanced social development.

\section{Connotation of "people-oriented"}

1.1 Health education highlights the importance of people

Nowadays, the domestic education requires us to pay more attention to the "people-oriented" sports education concept, improve the "people-oriented" thought and really protect people's independent thought while attaching great importance to the cultural course. By summarizing the previous experience, analyzing the literature document and comparing the students' health education and sports education, the importance of health education in the sports education is summed up to guide the correct implementation method and thought of health education. In addition, it shows the importance of health education and the need of giving play to people's subjective initiative. Here, the health education is not just limited to physical health and also a health concept that guides students to develop their physical health and strengthen their physical and psychological health, which is the health in a macroscopic sense. The emphasis on "people-oriented" shows the progress and development of human civilization.

1.2 "People-oriented" shows the respect and understanding to people

Due to the understanding and respect to humanity, we often consider others' feelings while doing something and the care of friends and the respect to friends are the basic annotation of "people-oriented". Similarly, college students should be respected, protected and cared in receiving education to make them strengthen their interests in new things according to their will. Therefore, the teacher should respect the students' thinking and encourage them to imagine and give play to their subjective initiative. The students should have their own hobbies, ambitions and pursuits. The adherence to "people-oriented" will make passionate college students realize their own value.

1.3 Disadvantage of traditional education

Under the impact of "people-oriented" and traditional education, the disadvantages of traditional education are prominent. For example, the traditional education neglects the respect to people, requires students to be uniform and fails to manifest students' personality, thus students' initiative is restrained and they cannot adapt to the social progress and have personality development. Some students like playing sports have no control right, thus they have no interest in sports subject and lack of active consciousness in class, thus forming a vicious cycle. The students fail to give play to 
their subject role as they are not active.

\section{Analysis of "people-oriented" education concept}

\subsection{Correctly build "people-oriented" teaching concept}

The teacher should respect the personality of each students, encourage them to give play to their personality characteristics and not combat their initiative. The teacher should also get rid of forbidden thought and better respect people's thought. Therefore, the teacher should change the original fixed education method, combine the original education concept and existing education method to improve the education method, improve the education system and stress the importance of people. In addition, the students, with development potential and special value, are the subject and emotional individuals with independent personality, and need and long for being respected and communicate with people in a manner they like. Students are an important role in the development of times, who represent the development of a generation, with deep potential and great importance. The sports teaching should concern and care students' needs, respect their emotions and admit their subject status. In various teaching links, the teacher should put the initiative and all-round development of students at the first place and mainly guide their learning interest. In this way, the students can form good learning habits. For this purpose, the teacher and students should cooperate with each other and the teacher should treat students equally and meet their needs and hobbies as far as possible. The teacher should also teach lessons and items that conform to the students' physical and psychological development, create relaxed and happy classroom atmosphere, improve their learning initiative and promote their physical and psychological health development.

2.2 Build "people-oriented" health concept

Health is a topic that we pay attention to at any time, which does not only refer to no physical disease, but also cover a healthy state psychologically. This extends the definition of traditional health and also requires the sports teacher not only to care students' physical health and strengthen their physique, but also to concern their psychological health and social activity ability, improve their life and guide them to be positive and optimistic. Sports can improve students' physique and psychological quality. Most of the sports teachers do not know the university is a treasured place to cultivate college students' ability of dealing with affairs and doing things and also can make them release their body and mind and relieve their emotions while playing sports. Therefore, the sports teacher should guide them to be optimistic, sunny and positive while teaching them how to strengthen the physique, consciously combine the movement technique and teaching concept to promote the common healthy development of college students' physical and psychological quality.

2.3 Give play to the subjectivity

The development of students' subjectivity is a perfect embodiment of "people-oriented" education method in college teaching. The original intention of education is to develop, educate and perfect people. Therefore, the education aims at cultivating students' subjectivity. The subjectivity is divided into independence, subjective initiative, autonomy and innovation, which is a judgment of student's ability, value orientation and other attributes. The education, which is an important medium that promotes the human development, can improve man's quality, perfect the cognitive system and pay attention to the cultivation of student subject. The topic of nowadays society is to promote the subjectivity of one's own conditions and the college provides a battlefield for students that can give play to man's subjective initiative.

2.4 Improve the assessment method

To improve the assessment method, it is required to innovate the sports management system of colleges, fully and really realize the popularization of sports education, in which the management activity plays a role in connecting the preceding and the following. While the popular goal of higher education is understood, the software and hardware resources are used to achieve such goal. It can be said that the management method directly affect the realization of the popularization of higher education. With rich teacher resource and complete teaching facilities, the initiative of the students and the teacher will also decrease if the traditional standard-type management method is still adopted, the traditional and existing facilities are not matched and the teaching links cannot be 
connected. For management, the assessment method is the most important among goal, measure and other content. The assessment method of learning outcomes and teaching results plays an important role in guiding the whole management system. Therefore, to change the sports management system of colleges, the most important is to change the sports education assessment method of colleges.

\section{Enlightenment of "people-oriented" teaching reform}

\subsection{Build the new goal of sports teaching content of colleges}

When the traditional education does not adapt to the social development, it is required to reform the sports teaching, get rid of its shortcoming and take its advantage, conduct in-depth summarization, set new goal, and make the social development goal and students' individual goal consistent to promote social development and cultivate students into socially desirable new talents. However, while the society asks the students to satisfy the social development, the society is also required to meet students' needs, improve their social initiative, cultivate their interests and make them development and imagine freely because the teaching goal can be achieved only by combing the two. The sports teacher is required to pay attention to the social value upon education, cultivate students' interests and hobbies, make students form good sports spirits and habits as well as a social morality, attach great importance to exercise, keep exercise, maintain physical and psychological heath and realize the harmonious development of social value system.

3.2 Emphasize the sustainable development of sports education content

The transition from the single teaching of the body movement of sports skills in the traditional education to the understanding and application of spirit, knowledge and skills in the modern education plus the diversity of sports events add the color of sports, arouse students' interests in sports internally, realize the upgrade of sports hobby subjectively, enhance students' interests and promote their all-around development.

3.3 Respect student's subject status

As the name suggests, people-oriented is to respect students and also the core of "people-oriented" sports education. It is required to pay attention to the cultivation of students independent personality and independence, conduct their self-cognition and self-improvement in practice and cultivate their innovative consciousness and ability of accepting new things. Therefore, the teacher should break the routines, focus on students, change the key points of textbook, aim at making students know the textbook law and arousing their learning motivation and intelligence, promote their thinking activity and improve their learning ability.

3.4 Adopt proper method and means in "people-oriented" education

The traditional teaching method is unilateral. Based on this, it is required to perfect the traditional teaching method, innovate the "people-oriented" teaching concept, implement the subject teaching strategy that the teacher and students follow and change the unilateral infusion of the teacher into the teacher-guided happy learning. On the premise of concerning the different quality of individuals, the teacher should also ensure the growth of every student, combine all kinds of development level for comprehensive development. In addition, the teacher should also fully develop students' creativity, cultivate their innovative consciousness and promote their all-around development while paying attention to the consist overall development goal.

3.5 "People-oriented" fully manifests the important role of sports teaching in teaching

"People-oriented" pays attention to the important role of people, which requires correctly giving play to man's subjective initiative. The value of people is an important precondition and the teacher is important because the teacher plays a leading role and will directly affect students' physical and psychological health, so the teacher will fail to play a leading role and directly make students' thought fall behind if the teacher's thinking cannot keep up with the development. Therefore, the selection of teacher is the most important link. In the sports education, it is required to train the teacher to accept the modern teaching concept and make them realize the importance of modern education to promote the reform and development of sports teaching in colleges. 


\section{4. "People-oriented" teaching concept should respect the humanistic spirit}

\subsection{Humanistic spirit is the core idea of "people-oriented"}

The humanistic spirit, which is the soul for the development of college sports education and also an important force to encourage the development of college sports education, leads college students to take a path of healthy development, embodies the unique nature of the education institution of college education and reflects the intrinsic requirement of all-around development and healthy physical and psychological development of college students. The development of the humanistic spirit of college sports fully manifests the good realization of sports value and cultivation of humanistic spirit. Under the macro-environment of rapid social economic development, the development of the humanistic spirit of college sports education is also highlighted and the important thought, "people-oriented", is converted into practical and reliable action, thus realizing perfect transformation.

4.2 Importance of "people-oriented" and developing humanistic spirit

As one is easily affected by the environment he is in, so the environment is very important. While improving the humanistic spirit, it is required to create a campus cultural environment that pays more attention to the humanistic spirit and also create a harmonious and healthy living atmosphere. Protecting the campus humanistic spirit is the responsibility of every college students, like protecting our home. Living in the simple, relaxed and happy campus, it can improve the self-quality and responsibility consciousness, perfect the modern education teaching concept and promote the development of times, economy and humanistic spirit.

4.3 Improve the teacher quality and establish harmonious teacher-student relationship

The humanistic feelings between the teacher and students are based on mutual understanding and friendliness and the teaching effects can be realized only by teaching in a good interpersonal atmosphere and mutual acceptance. This is a cooperative relationship based on democracy, equality, understanding and mutual respect and the cooperation should be win-win and harmonious, rather than class relations. The teacher is the instructor and also senior from the age and friend from the personality, thus establishing good teacher-student relationship. The teacher should adhere to "people-oriented" and guide and encourage students patiently to improve their confidence in learning. The teacher should also guide students to study deeper academic problems, solve some unsolved problems, make them think freely, awaken their thirst for knowledge and arouse their learning interests.

4.4 Integration of humanistic spirit and sports teaching

In teaching, the humanistic spirit and sports teaching should be effectively integrated with each other to promote the all-around healthy development of students. In teaching method, the humanistic spirits should be developed fully. The traditional teaching method is only limited to the teaching mode that the teacher reads and the students write, which seriously restrains the students from developing their personality, changes the interesting sports subject into a boring one, suppresses students' interests and makes them not develop their temperament and interest and not release their optimistic personality, thus becoming an stumbling block of their healthy growth.

\section{Conclusion}

After entering the new century, the college sports in China also looks forward to the arrival of an era with return of humanity personality respect. In such era, students can feel happy in learning sports and their needs of showing selves and extending individuality can be satisfied. However, it should be noted that we advocates developing humanity liberalism and manifesting the personality, rather than criticizing and denying other education thoughts. Actually, under the background that the education concepts worldwide are integrated with each other and have checks and balances, a diversified situation occur and all kinds of theories and thoughts argue with each other and are integrated with each other, which will certainly promote the prosperous development of sports in China. 


\section{References}

[1] Sun Ziling, Di Liwu. Enlightenment of "People-oriented" Educational View on Sports Teaching Reform of Colleges[J]. Journal of Physical Education, 2003(01).

[2] Zhang Hongbin. Research on Humanistic Quality Education in Colleges in China[D]. Journal of Daliann Maritime University, 2012.

[3] Huang Yingchun. "People-oriented" Sports Teaching New Concept of Colleges[J]. Journal of Bohai University (Natural Science), 2005(03). 